\title{
Profiles of second- to fourth-order moments of turbulent temperature fluctuations in the convective boundary layer: first measurements with rotational Raman lidar
}

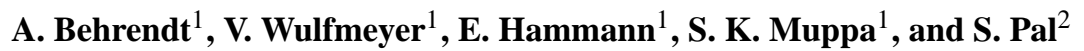 \\ ${ }^{1}$ University of Hohenheim, Institute of Physics and Meteorology, 70599 Stuttgart, Germany \\ ${ }^{2}$ University of Virginia, Department of Environmental Sciences, Charlottesville, VA 22904, USA
}

Correspondence to: A. Behrendt (andreas.behrendt@uni-hohenheim.de)

Received: 9 July 2014 - Published in Atmos. Chem. Phys. Discuss.: 21 November 2014

Revised: 21 April 2015 - Accepted: 25 April 2015 - Published: 20 May 2015

\begin{abstract}
The rotational Raman lidar (RRL) of the University of Hohenheim (UHOH) measures atmospheric temperature profiles with high resolution $(10 \mathrm{~s}, 109 \mathrm{~m})$. The data contain low-noise errors even in daytime due to the use of strong UV laser light $(355 \mathrm{~nm}, 10 \mathrm{~W}, 50 \mathrm{~Hz})$ and a very efficient interference-filter-based polychromator. In this paper, the first profiling of the second- to fourth-order moments of turbulent temperature fluctuations is presented. Furthermore, skewness profiles and kurtosis profiles in the convective planetary boundary layer (CBL) including the interfacial layer (IL) are discussed. The results demonstrate that the UHOH RRL resolves the vertical structure of these moments. The data set which is used for this case study was collected in western Germany ( $50^{\circ} 53^{\prime} 50.56^{\prime \prime} \mathrm{N}, 6^{\circ} 27^{\prime} 50.39^{\prime \prime} \mathrm{E}$; 110 ma.s.l.) on 24 April 2013 during the Intensive Observations Period (IOP) 6 of the $\mathrm{HD}(\mathrm{CP})^{2}$ (High-Definition Clouds and Precipitation for advancing Climate Prediction) Observational Prototype Experiment (HOPE). We used the data between 11:00 and 12:00 UTC corresponding to $1 \mathrm{~h}$ around local noon (the highest position of the Sun was at 11:33 UTC). First, we investigated profiles of the total noise error of the temperature measurements and compared them with estimates of the temperature measurement uncertainty due to shot noise derived with Poisson statistics. The comparison confirms that the major contribution to the total statistical uncertainty of the temperature measurements originates from shot noise. The total statistical uncertainty of a 20 min temperature measurement is lower than $0.1 \mathrm{~K}$ up to $1050 \mathrm{~m}$ a.g.l. (above ground level) at noontime; even for single $10 \mathrm{~s}$ temperature profiles, it is smaller than $1 \mathrm{~K}$ up to $1020 \mathrm{~m}$ a.g.l. Autocovariance and spectral analyses of the at-
\end{abstract}

mospheric temperature fluctuations confirm that a temporal resolution of $10 \mathrm{~s}$ was sufficient to resolve the turbulence down to the inertial subrange. This is also indicated by the integral scale of the temperature fluctuations which had a mean value of about $80 \mathrm{~s}$ in the CBL with a tendency to decrease to smaller values towards the CBL top. Analyses of profiles of the second-, third-, and fourth-order moments show that all moments had peak values in the IL around the mean top of the CBL which was located at $1230 \mathrm{~m}$ a.g.l. The maximum of the variance profile in the IL was $0.39 \mathrm{~K}^{2}$ with 0.07 and $0.11 \mathrm{~K}^{2}$ for the sampling error and noise error, respectively. The third-order moment (TOM) was not significantly different from zero in the CBL but showed a negative peak in the IL with a minimum of $-0.93 \mathrm{~K}^{3}$ and values of 0.05 and $0.16 \mathrm{~K}^{3}$ for the sampling and noise errors, respectively. The fourth-order moment (FOM) and kurtosis values throughout the CBL were not significantly different to those of a Gaussian distribution. Both showed also maxima in the IL but these were not statistically significant taking the measurement uncertainties into account. We conclude that these measurements permit the validation of large eddy simulation results and the direct investigation of turbulence parameterizations with respect to temperature.

\section{Introduction}

Temperature fluctuations and their vertical organization inherently govern the energy budget in the convective planetary boundary layer (CBL) by determining the vertical heat flux 
and modifying the interaction of vertical mean temperature gradient and turbulent transport (Wyngaard and Cote, 1971; Wyngaard, 2010). Thus, the measurement of turbulent temperature fluctuations and characterizations of their statistics are essential for solving the turbulent energy budget closure (Stull, 1988). In situ measurements (near the ground, on towers, or on airborne platforms) sample certain regions of the CBL within certain periods and have been used for a long time for turbulence studies. But to the best of our knowledge, there are no previous observations based on a remote-sensing technique suitable for this important task, i.e., resolving temperature fluctuations in high resolution and covering simultaneously the CBL up to the interfacial layer (IL). In this work, it is demonstrated that rotational Raman lidar (RRL) (Cooney, 1972; Behrendt, 2005) can fill this gap.

By simultaneous measurements of turbulence at the land surface and in the IL, the flux divergence and other key scaling variables for sensible and latent heat entrainment fluxes can be determined, which is key for the evolution of temperature and humidity in the CBL and thus for verifying turbulence parameterizations in mesoscale models (Sorbjan, 1996, 2001, 2005).

Traditionally, studies of turbulent temperature fluctuations in the atmospheric CBL were performed with in situ instrumentation operated on tethered balloons, helicopters, and aircraft (e.g., Clarke et al., 1971; Muschinski et al., 2001) as well as recently with unmanned aerial vehicles (UAVs, e.g., Martin et al., 2011). However, it is not possible to obtain instantaneous profiles of turbulent fluctuations with in situ sensors and it is difficult to identify the exact location and characteristics of the IL. Recently, it was demonstrated that the combination of remote-sensing instruments (for guiding) and a UAV also allows for the study of entrainment processes at the CBL top (Martin et al., 2014). However, the UAV cannot continuously examine the processes due to its short endurance.

For studying turbulent processes and their parameterizations, however, it is essential that the turbulent transport and the temperature gradient are measured simultaneously in the same volume. Therefore, the shortcomings of in situ observations call for new remote-sensing technologies. These instruments can be operated on different platforms and can provide excellent long-term statistics, if applied from groundbased platforms. Passive remote-sensing techniques, however, show difficulties in contributing to turbulence studies because of their inherent limitation in range resolution which flattens turbulent fluctuations. Nevertheless, Kadygrov et al. (2003) published a study on turbulent temperature fluctuations based on passive remote-sensing techniques. The authors used a scanning microwave temperature profiler to investigate thermal turbulence and concluded that the spectral density of brightness temperature fluctuations at $75 \mathrm{~m}$ above ground indeed followed the expected $-5 / 3$-power law of Kolmogorov (1991). Kadygrov et al. (2003) concluded that "measurements can be provided in all weather conditions, but the technique has limitations in altitude range" as their turbulence studies could only reach up to a maximum height of $200 \mathrm{~m}$.

In recent years, new insights in CBL turbulence were provided by studies based on active remote sensing with different types of radar and lidar systems. Radar wind profilers were used to study the vertical CBL wind profile and its variance (e.g., Angevine et al., 1994; Eng et al., 2000; Campistron et al., 2002). A radio-acoustic sounding system (RASS) provides profiles of virtual temperature which can be used as a scaling parameter for turbulence studies also in higher altitudes (e.g., Hermawan and Tsuda, 1999; Furomoto and Tsuda, 2001). But temperature and moisture fluctuations cannot be separated with RASS. Furthermore, the RASS profiles have typical resolutions of a few minutes which is too large to resolve the inertial subrange. In addition to radar, lidar techniques have also been used for turbulence studies: elastic backscatter lidar (Pal et al., 2010, 2013), ozone differential absorption lidar (ozone DIAL) (Senff et al., 1996), Doppler lidar (e.g., Lenschow et al., 2000, 2012; Wulfmeyer and Janjic, 2005; O'Connor et al., 2010; Träumner et al., 2015), water vapor differential absorption lidar (WV DIAL) (e.g., Senff et al., 1994; Kiemle et al., 1997; Wulfmeyer, 1999a; Lenschow et al., 2000; Muppa et al., 2015), and water vapor Raman lidar (e.g., Wulfmeyer et al., 2010; Turner et al., 2014a, b) have been employed or a combination of these techniques (e.g., Giez et al., 1999; Wulfmeyer, 1999b; Kiemle et al., 2007, 2011; Behrendt et al., 2011a; Kalthoff et al., 2013). However, so far, profiling of turbulent temperature fluctuations with active remote sensing was missing.

In general, daytime measurements are more challenging than nighttime measurements for lidar because of the higher solar background which increases the signal noise and even prohibits measurements for most Raman lidar instruments. In order to address the measurement needs, the University of Hohenheim (UHOH) RRL was optimized for high temperature measurement performance in daytime in the CBL (Radlach et al., 2008). The data of the UHOH RRL have already been used for studies on the characterization of transport and optical properties of aerosol particles near their sources (Behrendt et al., 2011b; Valdebenito et al., 2011), on the initiation of convection (Groenemeijer et al., 2009; Corsmeier et al., 2011), and on atmospheric stability indices (Behrendt et al., 2011; Corsmeier et al., 2011). Here, the formalism introduced by Lenschow et al. (2000) is applied for the first time to the data of an RRL to study the extension of the variable set of lidar turbulence studies within the CBL to temperature.

The measurements discussed here were carried out at around local noon (11:33 UTC) on 24 April 2013 during the Intensive Observations Period (IOP) 6 of the $\mathrm{HD}(\mathrm{CP})^{2}$ (High-Definition Clouds and Precipitation for advancing Climate Prediction) Observational Prototype Experiment (HOPE), which is embedded in the project $\operatorname{HD}(\mathrm{CP})^{2}$ of the German Research Ministry. The UHOH RRL was posi- 
tioned during this study at $50^{\circ} 53^{\prime} 50.56^{\prime \prime} \mathrm{N}, 6^{\circ} 27^{\prime} 50.39^{\prime \prime} \mathrm{E}$, $110 \mathrm{~m}$ a.s.l. near the village of Hambach in western Germany where it performed measurements between 1 April and 31 May 2013.

This paper is organized as follows. In Sect. 2, the setup of the UHOH RRL is described briefly; more details can be found in Hammann et al. (2015). The meteorological background and turbulence measurements are presented in Sect. 3. Finally, conclusions are drawn in Sect. 4.

\section{Setup of the UHOH RRL}

The RRL technique is based on the fact that different portions of the pure rotational Raman backscatter spectrum show different temperature dependence. By extracting signals out of these two portions and forming the signal ratio, one obtains a profile which, after calibration, yields a temperature profile of the atmosphere (see, e.g., Behrendt, 2005, for details).

A scheme of the UHOH RRL during HOPE is shown in Fig. 1. Key system parameters are summarized in Table 1. As laser source, an injection-seeded frequency-tripled $\mathrm{Nd}$ :YAG laser $(354.8 \mathrm{~nm}, 50 \mathrm{~Hz}, 10 \mathrm{~W})$, model GCR $290-50$ of Newport Spectra-Physics GmbH, is used. The UV laser radiation is separated from the fundamental and frequency-doubled radiation near 532 and $1064 \mathrm{~nm}$, respectively, with a PellinBroca prism (PBP), so that only the UV radiation is sent to the atmosphere. This improves eye safety significantly compared to systems which use harmonic beam splitters because there is definitely no potentially hazardous green laser light present in the outgoing laser beam. But the main reason for using UV laser radiation for the transmitter of the UHOH RRL is that the backscatter cross section is proportional to the inverse wavelength to the fourth power. This yields significantly stronger signals and thus lower statistical uncertainties of the measurements in the lower troposphere (see also Di Girolamo et al., 2004, 2006; Behrendt, 2005) when using the third harmonic instead of the second harmonic of Nd:YAG laser radiation. Behind the PBP, the laser beam is expanded 6.5-fold in order to reduce the beam divergence to $<0.2 \mathrm{mrad}$. The laser beam is then guided by three mirrors parallel to the optical axis of the receiving telescope (coaxial design) and reflected up into the atmosphere by two scanner mirrors inside of a so-called beam-steering unit (BSU). The same two mirrors reflect the atmospheric backscatter signals down to the receiving telescope which has a primary mirror diameter of $40 \mathrm{~cm}$. The scanner allows for full hemispherical scans with a scan speed of up to $10^{\circ} \mathrm{s}^{-1}$. In the present case study, the scanner was pointing constantly in vertical direction. In the focus of the telescope, a field-stop iris defines the field of view. For the data shown here, an iris diameter of $3 \mathrm{~mm}$ was selected which yielded a telescope field of view of $0.75 \mathrm{mrad}$. The light is collimated behind the iris with a convex lens and enters a polychromator which contained three channels during the discussed measurements: one chan-

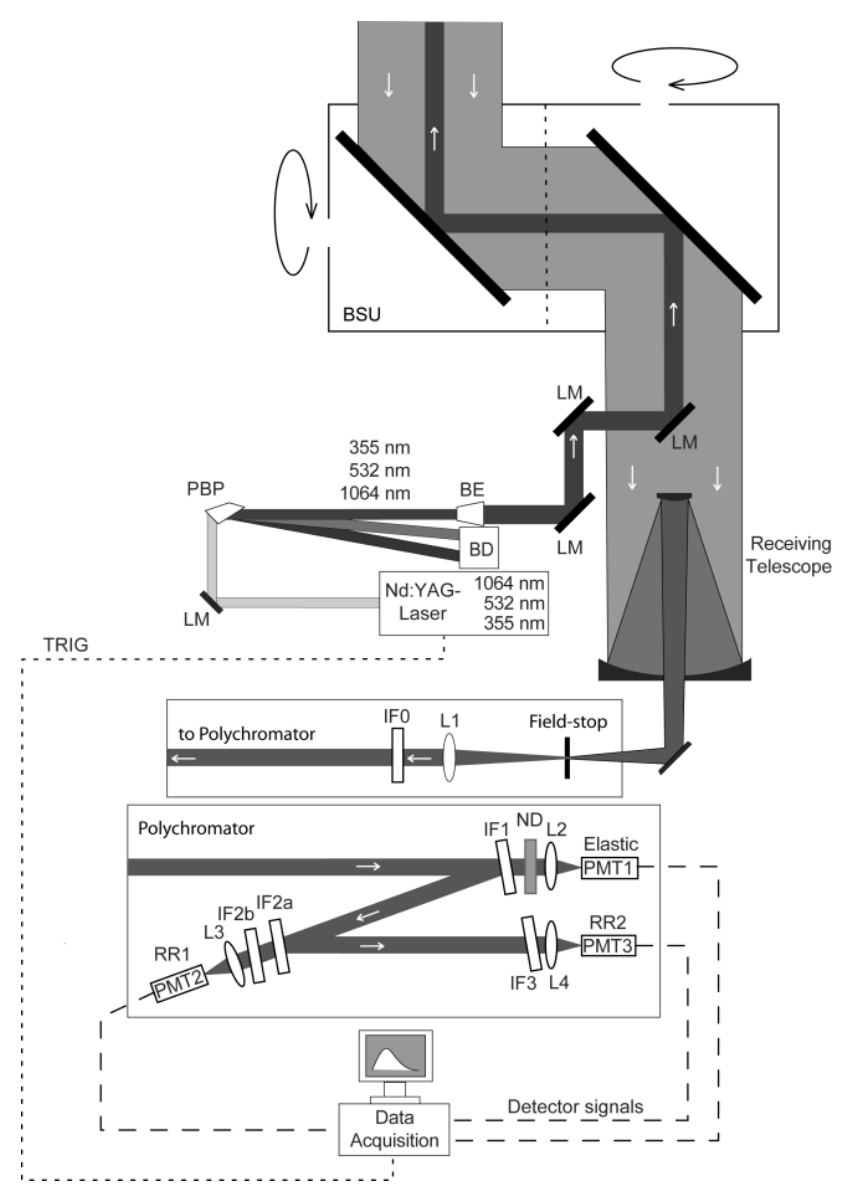

Figure 1. Scheme of the UHOH RRL. The beam-steering unit (BSU) consists of two plane mirrors which scan the laser beam and receiving telescope field-of-view. LM: laser mirror; PBP: PellinBroca prism; BE: beam expander; BD: beam dump; L1 to L4: lenses; IF0 to IF3: interference filters; PMT1 to PMT3: photomultiplier tubes; RR1 and RR2: rotational Raman channel 1 and 2, respectively. The beam splitter for the water vapor Raman channel between L1 and IF0 has been omitted for clarity here.

nel for collecting atmospheric backscatter signals around the laser wavelength (elastic channel) and two channels for two signals from different portions of the pure rotational Raman backscatter spectrum. During the HOPE campaign, the polychromator was later extended with a water vapor Raman channel; the beam splitter for this channel was already installed during the measurements discussed here. Within the polychromator, narrow-band multi-cavity interference filters extract in a sequence the elastic backscatter signal and the two rotational Raman signals with high efficiency. The filters are mounted at angles of incidence of about $5^{\circ}$. This setting allows for high reflectivity of the signals of the channels following in the chain (Behrendt and Reichardt, 2000; Behrendt et al., 2002, 2004). The filter passbands were optimized within detailed performance simulations for measurements in the CBL in daytime (Behrendt, 2005; Radlach et al., 
Table 1. Overview of key parameters of the rotational Raman lidar of University of Hohenheim (UHOH RRL) during the measurements discussed here.

\begin{tabular}{ll}
\hline Transmitter & $\begin{array}{l}\text { Flash-lamp-pumped injection-seeded frequency-tripled Nd:YAG laser } \\
\text { Pulse energy: } \sim 200 \mathrm{~mJ} \text { at } 354.8 \mathrm{~nm} \\
\text { Repetition rate: } 50 \mathrm{~Hz} \\
\text { Pulse duration: } \sim 5 \mathrm{~ns}\end{array}$ \\
\hline Receiver & $\begin{array}{l}\text { Diameter of primary mirror: } 40 \mathrm{~cm} \\
\text { Focal length: } 4 \mathrm{~m}\end{array}$ \\
& Field of view: $0.75 \mathrm{mrad}$ (selectable) \\
\hline Scanner & Manufactured by the NCAR, Boulder, CO, USA \\
& Mirror coating: protected aluminum \\
& Scan speed: up to $10^{\circ} \mathrm{s}-1$ \\
\hline Detectors & Photomultiplier tubes, Hamamatsu R7400-U02 (Elastic), R1924P (RR1+2) \\
\hline Data acquisition system & 3 -channel transient-recorder, LICEL GmbH, Germany \\
\hline Range resolution & $3.75 \mathrm{~m}$ in analog mode up to $30 \mathrm{~km}$ range \\
& $3.75 \mathrm{~m}$ in photon-counting mode up to $30 \mathrm{~km}$ range \\
& $37.5 \mathrm{~m}$ in photon-counting mode up to $75 \mathrm{~km}$ range \\
\hline
\end{tabular}

2008; Hammann et al., 2015). The new daytime/nighttime switch for the second rotational Raman channels (Hammann et al., 2015) was set to daytime optimizing the signal-to-noise ratio of the RR2 channel for high-background conditions. Further details on the receiver setup and the filter passbands can be found in Hammann et al. (2015).

\section{Turbulence case study}

\subsection{Data set}

The synoptic condition on 24 April 2013 was characterized by a large high-pressure system over central Europe. Because no clouds were forecasted for the HOPE region, this day was announced as Intensive Observation Period (IOP) 6 with the goal to study CBL development under clearsky conditions. Indeed, undisturbed solar irradiance resulted in the development of a CBL which was not affected by clouds. A radiosonde launched at the lidar site at 11:00 UTC showed moderate westerly winds throughout the CBL and also in the lower free troposphere. The horizontal speeds were $<2 \mathrm{~m} \mathrm{~s}^{-1}$ near the ground increasing to about $5 \mathrm{~m} \mathrm{~s}^{-1}$ in the CBL between about 100 and $1000 \mathrm{~m}$ a.g.l. (above ground level). Between 1000 and $1300 \mathrm{~m}$ a.g.l., the horizontal wind increased further to about $10 \mathrm{~m} \mathrm{~s}^{-1}$ while ranging between this value and $8 \mathrm{~m} \mathrm{~s}^{-1}$ in the lower free troposphere; $3 \mathrm{~m}$ temperatures at the lidar site increased between 09:00 and 11:00 UTC from 280 to $294 \mathrm{~K}$. The sensible heat flux at noon was about $170 \mathrm{~W} \mathrm{~m}^{-2}$ at the lidar site.

The time-height plot of the particle backscatter coefficient $\beta_{\text {par }}$ (Fig. 2) between 11:00 and 12:00 UTC shows the CBL height around local noon (11:33 UTC with a maximum solar elevation of $54^{\circ}$ on this day). $\beta_{\text {par }}$ was measured with the rotational Raman lidar technique by use of a temperatureindependent reference signal (Behrendt et al., 2002). Data below $400 \mathrm{~m}$ were affected by incomplete geometrical overlap of the outgoing laser beam and the receiving telescope and have been excluded from this study.

As seen in Fig. 2, indeed no clouds were present in this period. The CBL is clearly marked by higher values of $\beta_{\text {par }}$ which result from aerosol particles which are lifted up from the ground into the CBL. The instantaneous CBL height was determined with the Haar-wavelet technique which detects the strongest gradient of the aerosol backscatter signal as tracer (Pal et al., 2010, 2012; Behrendt et al., 2011a) (Fig. 2). The mean of the instantaneous CBL heights $z_{i}$ in the observation period was $1230 \mathrm{~m}$ a.g.l. This value is used in the following for the normalized height scale $z / z_{i}$. The standard deviation of the instantaneous CBL heights was $33 \mathrm{~m}$; the absolute minimum and maximum were 1125 and $1323 \mathrm{~m}$ a.g.l., i.e., the instantaneous CBL heights were within $200 \mathrm{~m}$. Besides its vertical structure, the $\beta_{\text {par }}$ field in the CBL also shows a temporal trend in this case which may be explained by changing aerosol number density or size distribution in the advected air over the lidar.

The temperature profile, which is the primary data product of the UHOH RRL, for the period of 11:00-11:20 UTC, is shown in Fig. 3 together with $z_{i}$ and the data of a local radiosonde launched at the lidar site at 11:00 UTC. Calibration of the RRL temperature data used in this study was made with these radiosonde data in the CBL between 400 and $1000 \mathrm{~m}$ a.g.l.; the RRL data above result from extrapolation of the calibration function. For the calibration, we used a 20 min average of the RRL data in order to reduce sampling effects between the two data sets. Longer averaging periods for the RRL reduce the statistical uncertainty of the measure- 


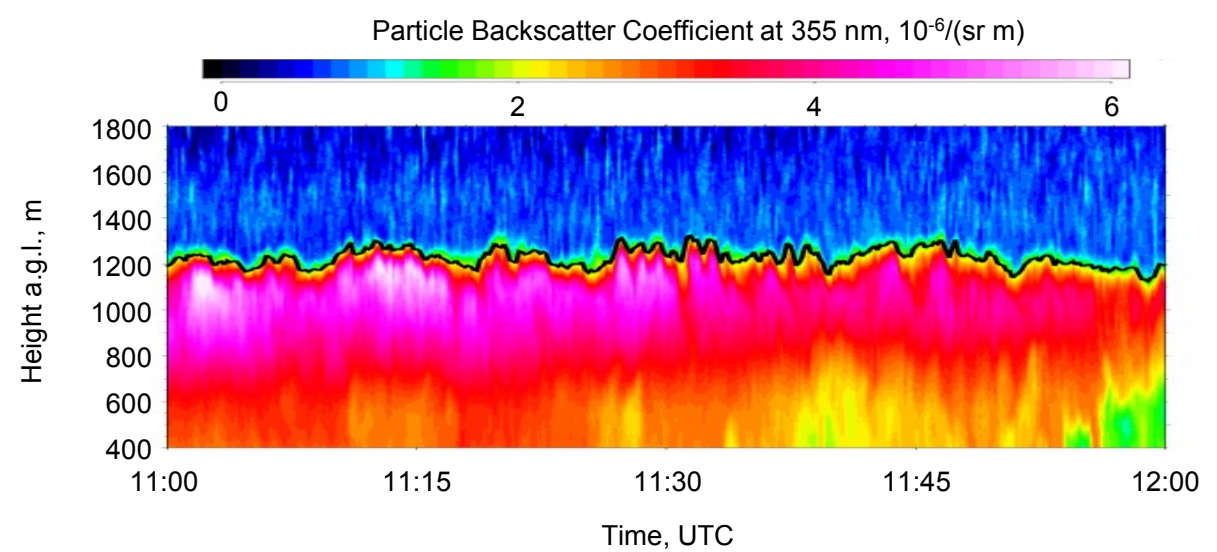

Figure 2. Time-height cross section of particle backscatter coefficient $\beta_{\text {par }}$ at $354.8 \mathrm{~nm}$ measured with the UHOH RRL on 24 April 2013 between 11:00 and 12:00 UTC. The temporal and spatial resolution of the data is $\Delta t=10 \mathrm{~s}$ and $\Delta z=3.75 \mathrm{~m}$ with a gliding average of $109 \mathrm{~m}$. The instantaneous CBL heights determined with the Haar-wavelet analysis of $\beta_{\text {par }}$ profiles are marked. a.g.l. (above ground level).

ments but increase the sampling differences; shorter averaging results in larger statistical errors and additionally in sampling of fewer air masses which makes the comparison with the snapshot data of the radiosonde more difficult. It would be optimum, of course, to track the sonde with the RRL but such a synchronization of the lidar scanner with the sonde is not yet possible with the UHOH RRL.

The uncertainty of the calibration depends mainly on the calibration of the radiosonde; their uncertainty is $<0.2 \mathrm{~K}$ (see http://www.graw.de/home/products2/radiosondes0/ radiosondedfm-090/ and Nash et al., 2011). It is noteworthy that the accuracy of the measured temperature fluctuations do not depend on the absolute accuracy of the temperature measurements but on their relative accuracy. Even with an error of $1 \mathrm{~K}$, the relative accuracy of the measured temperature fluctuations would be better than $(1 \mathrm{~K}) /(250 \mathrm{~K})=0.4 \%$. For the statistical analysis of the turbulent temperature fluctuations, we then used this calibration for the $1 \mathrm{~h}$ RRL data set between 11:00 and 12:00 UTC. This $1 \mathrm{~h}$ period seems here to be a good compromise: for much longer periods, the CBL characteristics may change considerably while shorter periods would reduce the number of sampled thermals and thus increase the sampling errors.

The temperature profiles of RRL and radiosonde shown in Fig. 3 agree within fractions of $1 \mathrm{~K}$ in the CBL. Larger differences occur in the IL due to the different sampling methods: the mean lidar profile shows an average over $20 \mathrm{~min}$, while the radiosonde data sample an instantaneous profile along the sonde's path which was determined by the drift of the sonde with the horizontal wind. In this case, the sonde needed about $5 \mathrm{~min}$ to reach the top of the boundary layer and drifted by about $1.6 \mathrm{~km}$ away from a vertical column above the site. Depending on the part of the thermal eddies in the CBL and the IL that are sampled, the radiosonde data thus represent different CBL features and are not representative for a mean profile (Weckwerth et al., 1996) which is a crucial point to be
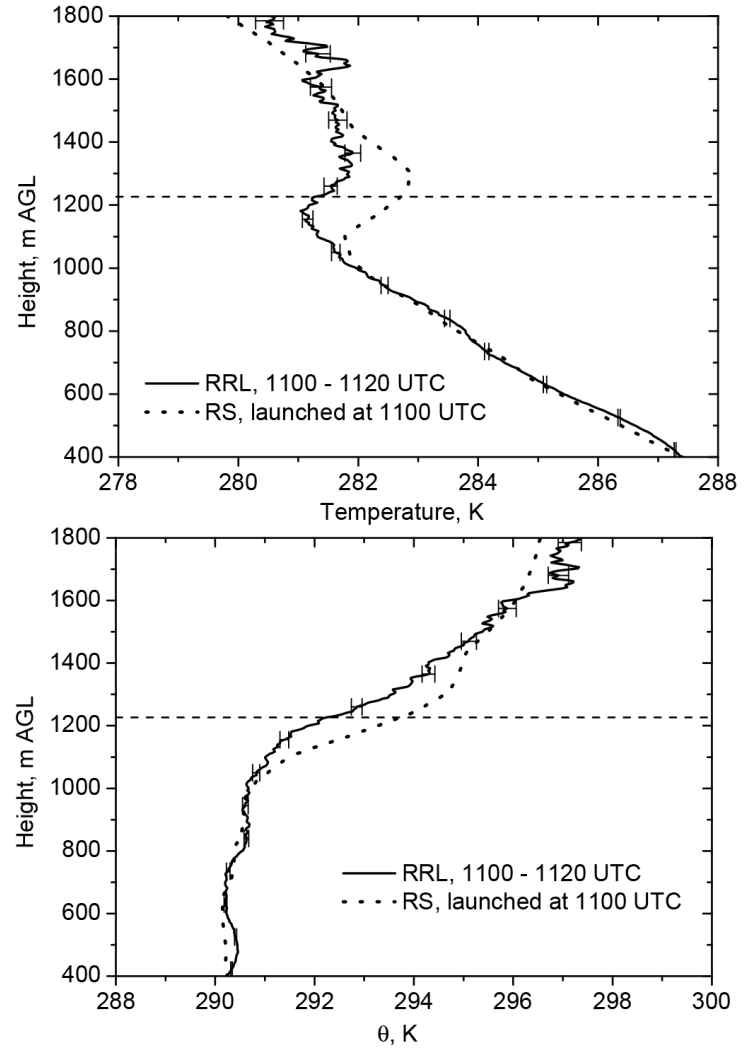

Figure 3. Upper panel: average temperature profile measured with the UHOH RRL on 24 April 2013 between 11:00 and 11:20 UTC and temperature profiles measured with a local radiosonde launched at the lidar site at 11:00 UTC. Lower panel: same but potential temperature profiles. The dashed line shows $z_{i}$ for comparison. Error bars show the uncertainties derived with Poisson statistics from the intensities of the rotational Raman signals. 


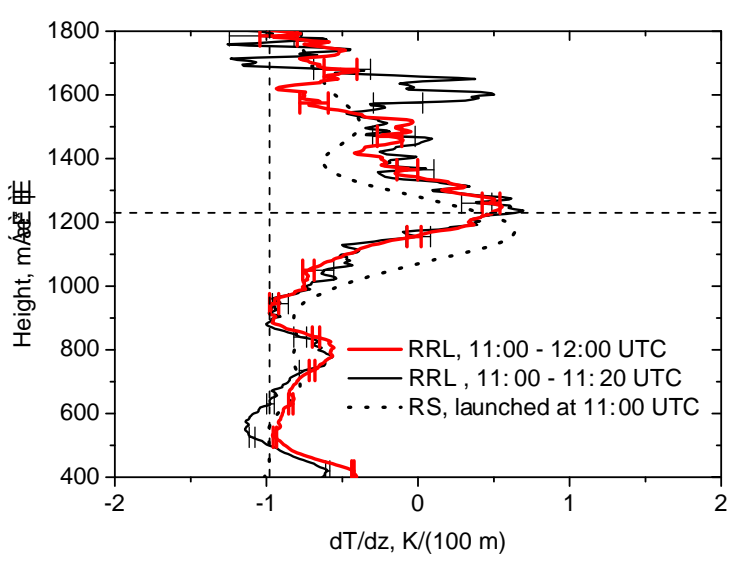

Figure 4. Average temperature gradients measured with the UHOH RRL on 24 April 2013 between 11:00 and 11:20 UTC, between 11:00 and 12:00 UTC and temperature gradient measured with a local radiosondes launched at the lidar site at 11:00 UTC. The horizontal dashed line shows $z_{i}$, the mean CBL top height for the period between 11:00 and 12:00 UTC, which agrees with the maximum temperature gradients of both RRL profiles. The vertical dashed line shows the dry-adiabatic temperature gradient. Error bars show the uncertainties derived with Poisson statistics from the intensities of the rotational Raman signals.

considered when using radiosonde data for scaling of turbulent properties in the CBL. Furthermore, averaged lidar temperature data are also more representative for a certain site for model validations.

Inside the CBL, the potential temperature (derived from the RRL temperature data with the radiosonde pressure profile) is nearly constant indicating a well-mixed CBL (Fig. 3, lower panel); $z_{i}$ lies approximately in the middle of the temperature inversion in the IL (Fig. 3). Figure 4 shows the temperature gradients of the radiosonde and the RRL profiles, the latter for two averaging periods, namely, 11:00 to 11:20 UTC and 11:00 to 12:00 UTC. The maximum temperature gradient is in this case very similar for all three profiles, i.e., between 0.6 and $0.7 \mathrm{~K} /(100 \mathrm{~m})$. It is interesting to note furthermore that the height of maximum temperature gradient agrees with $z_{i}$ for both RRL profiles as determined with the Haar-wavelet technique. In contrast to this, the height of the maximum temperature gradient in the radiosonde profile is about $60 \mathrm{~m}$ lower. But, as already mentioned, the radiosonde data are not representative for a mean profile.

\subsection{Turbulent temperature fluctuations}

For CBL turbulence analyses, the instantaneous value of temperature $T(z)$ at height $z$ is separated in a slowly varying component $\overline{T(z)}$ derived from applying a linear fit to the data typically over 30 to $60 \mathrm{~min}$ and the temperature fluctuation $T^{\prime}(z)$ according to, e.g., Wyngaard (2010)

$T(z)=\overline{T(z)}+T^{\prime}(z)$.
Figure 5 shows the time-height cross sections of temperature, potential temperature, and detrended temperature fluctuations $T^{\prime}(z)$ in the discussed period. For detrending, the same linear regression was applied to the temperature time series of all heights. Furthermore, the data set with the temperature fluctuations was gridded to exact $10 \mathrm{~s}$ time steps in order to ensure that all derived parameters are correct. (The vertical black lines in the lower panel of Fig. 5 are artifacts from this procedure.) One can see the positive and negative temperature fluctuations inside the CBL. In the IL, the fluctuations in the measured data become larger than in heights below. Above the CBL in the free troposphere, one finds fewer structures in the temperature fluctuations and mostly uncorrelated instrumental noise.

Lidar data contain significant stochastic instrumental noise, which has to be determined and for which has to be corrected in order to obtain the atmospheric fluctuation of a variable of interest. In general, the signal-to-noise ratio can be improved by averaging the signal in time and/or range but this in turn would of course reduce the ability to resolve turbulent structures. In principle, very high time resolution, i.e., the maximum allowed by the data acquisition system, is preferred in order to keep most frequencies of the turbulent fluctuations. But this is only possible as long as the derivation of temperature does not result in a non-linear increase of the noise errors; this noise regime should be avoided. A temporal resolution of $10 \mathrm{~s}$ turned out to be a good compromise for the temporal resolution of our data as explained below.

The variance of the atmosphere $\overline{\left(x_{\mathrm{a}}^{\prime}(z)\right)^{2}}$ and the noise variance $\overline{\left(x_{\mathrm{n}}^{\prime}(z)\right)^{2}}$ of a variable $x$ are uncorrelated. Thus, we can write (Lenschow et al., 2000)

$\overline{\left(x_{\mathrm{m}}^{\prime}(z)\right)^{2}}=\overline{\left(x_{\mathrm{a}}^{\prime}(z)\right)^{2}}+\overline{\left(x_{\mathrm{n}}^{\prime}(z)\right)^{2}}$

with $\overline{\left(x_{\mathrm{m}}^{\prime}(z)\right)^{2}}$ for the measured total variance. Overbars denote here and in the following temporal averages over the analysis period. The separation of the atmospheric variance from the noise contribution can be realized by different techniques. Most straightforward is the autocovariance method, which makes use of the fact that atmospheric fluctuations are correlated in time while instrumental noise fluctuations are uncorrelated. Further details were introduced by Lenschow et al. (2000) so that only a brief overview is given here. The atmospheric variance can be obtained from the autocovariance function (ACF) of a variable by extrapolating the tails (non-zero lags) to zero lag with a power-law fit (see Eq. 32 of Lenschow et al., 2000). As the ACF at zero lag is the total variance, the instrumental noise variance is the difference of the two. Alternatively, one may calculate the power spectrum of the fluctuations and use Kolmogorov's (1991) $-5 / 3$ law within the inertial subrange in order to determine the noise level (e.g., O'Connor et al., 2010). We prefer the ACF method to the spectral analysis because the ACF method is less prone to errors since the statistical noise does not show 

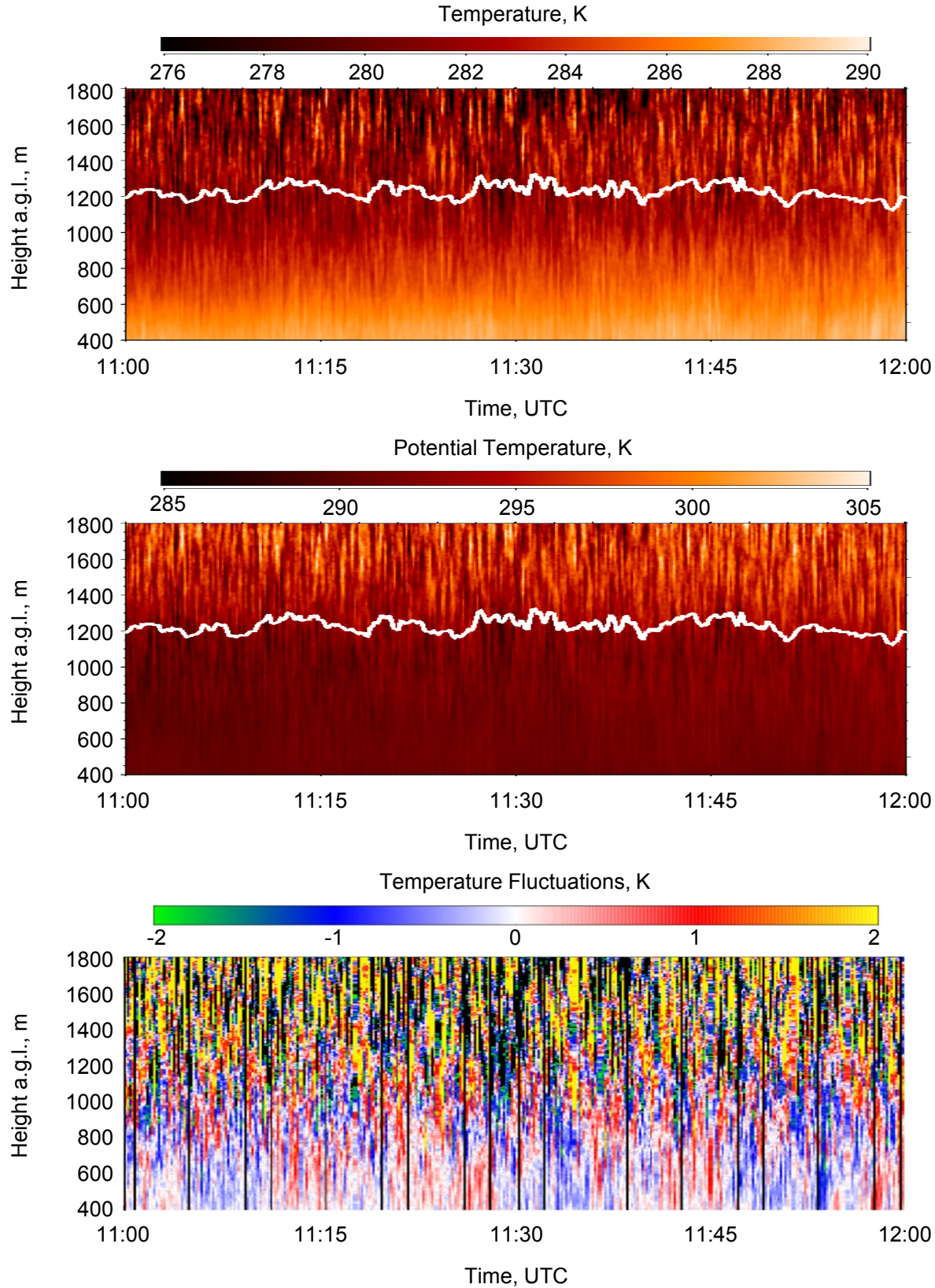

Figure 5. Same as Fig. 2 but for temperature, potential temperature, and detrended temperature fluctuations: time-height cross sections measured with the UHOH RRL on 24 April 2013 between 11:00 and 12:00 UTC. The temporal and spatial resolution of the data is $\Delta t=10 \mathrm{~s}$ and $\Delta z=3.75 \mathrm{~m}$ with a gliding average of $109 \mathrm{~m}$. The instantaneous CBL heights determined with the Haar-wavelet analysis are marked (same as shown in Fig. 2). a.g.l. (above ground level). (Black vertical lines are gaps which result from gridding the data to exact $10 \mathrm{~s}$ intervals; these artifacts do not influence the turbulence analysis.)

up at the non-zero lags which are used for the fit; the determination of the statistical noise level from the power spectra is more prone to errors.

Figure 6 shows the ACF obtained from the measured temperature fluctuations for heights between 400 and $1230 \mathrm{~m}$ a.g.l., i.e., 0.3 to $1.0 z_{i}$ for time lags from -200 to $200 \mathrm{~s}$. The increase of the values at zero lag with height shows mainly the increase of the statistical noise with height.
Different values of the ACF close to the zero lag show differences in the atmospheric variance at different heights.

The following question arises: what it the most suitable number of lags for the extrapolation of the structure function to lag zero? This has been discussed in Wulfmeyer et al. (2010) and Turner et al. (2014b) but here we are providing more details. We have applied the following procedure to the measured temperature fluctuations for the determination 

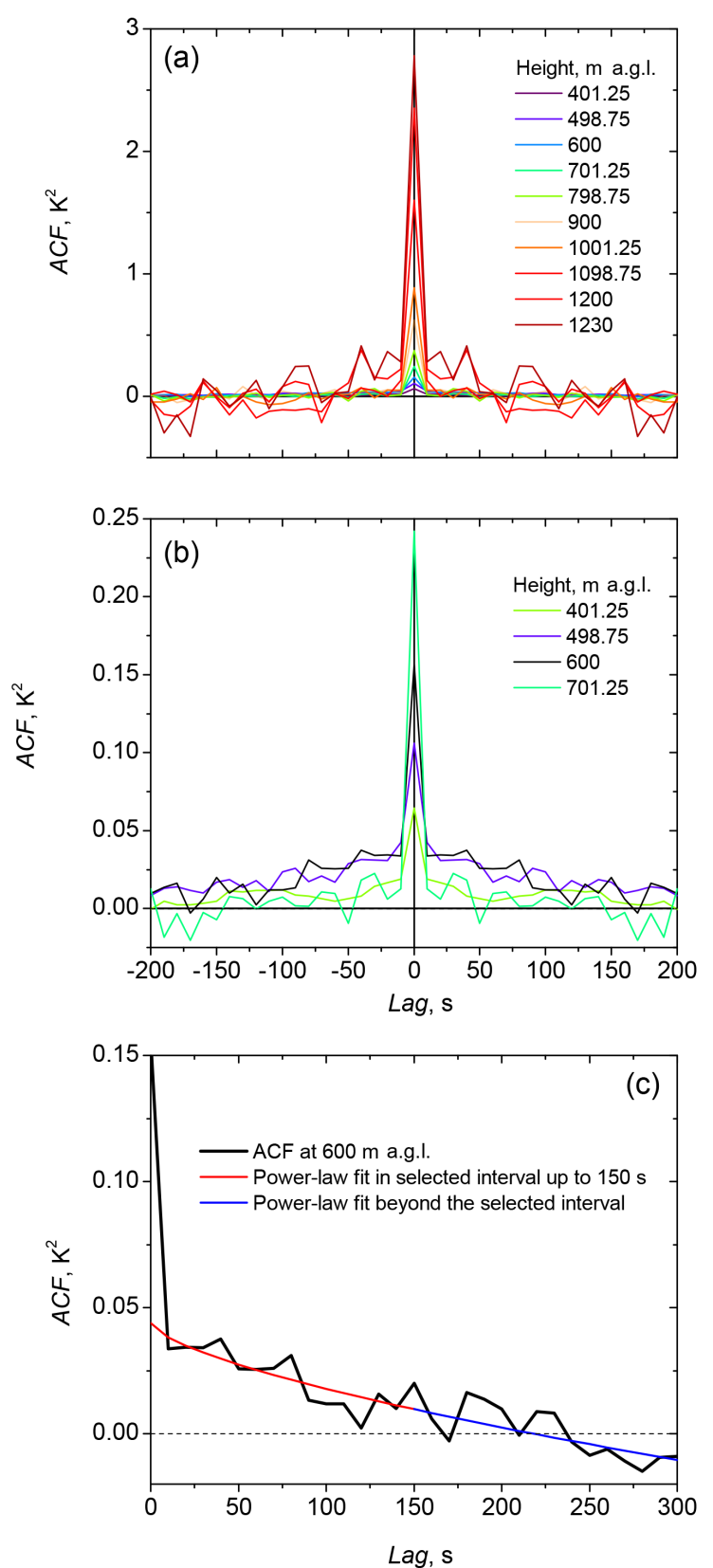

Figure 6. (a) Autocovariance functions (ACF) around the zero lag obtained at different heights from the temperature measurements shown in Fig. 5, i.e., with the data of 24 April 2013 between 11:00 and 12:00 UTC. (b) Zoom of (a) for lower heights only. (c) ACF with power-law fit for $600 \mathrm{~m}$ a.g.1.

of the integral scale, all higher-order moments, and for the separation of noise and atmospheric variances: first of all, the profile of the integral scale is derived using a standard number of lags. Usually, we are taking 20 time lags of $10 \mathrm{~s}$ covering thus $200 \mathrm{~s}$, as this turned out from previous measurements to be a value which is typically appropriate. The resulting integral scale is a measure of the mean size of an eddy in time. If the resulting integral scale is larger than the averaging time of the measured data, which is in this case $10 \mathrm{~s}$, one can state that the most important part of the turbulent fluctuations is resolved. It can be theoretically shown that the zero crossing of the ACF appears at 2.5 times the integral scale (Wulfmeyer et al., 2015). Thus, we are choosing $\leq 2.5$ times the mean value of the integral scale throughout the CBL as a reasonable number of fit lags. Please note that this refinement was not discussed in the literature before except only very recently by Turner et al. (2014b) and Wulfmeyer et al. (2015). Previously, very simple approaches were used such as just the value of the first lag as an approximation for the extrapolation to lag zero. Our approach is more appropriate and may further be refined by applying an iteration between the determination of the integral scale and the derivation of the optimal number of fit lags at each height. As the integral timescale has a mean of about $80 \mathrm{~s} \mathrm{in}$ the CBL corresponding to a mean zero crossing of the ACF at $200 \mathrm{~s}$, we finally decided to use 15 fit lags in this study (see Fig. 6c) which is on the safe side. We found that we can interrupt the iteration procedure in the first step because all resulting profiles are within the range of the noise error bars in this case regardless of whether we use 10,15 , or 20 fit lags. As a result, 15 fit lags finally seemed for us to be the best selection. For the higher-order moments, the same number of 15 fit lags was used as for the variance but here linear extrapolations to lag zero was applied (Lenschow et al., 2000). We consider this as best approach, as the shape of the higher-order structure function is still unknown to date.

\subsection{Noise errors}

The resulting profiles of the noise error of the temperature measurements

$\Delta T(z)=\sqrt{\overline{\left(T_{\mathrm{n}}^{\prime}(z)\right)^{2}}}$

are shown in Fig. 7 together with profiles of the errors due to shot noise derived with Poisson statistics from the signal intensities (as detailed below). Both profiles are similar but it should be noted that the autocovariance technique specifies the total statistical error, while the shot-noise error is a part of the total statistical error.

For calculating the shot-noise errors from the signal intensities, the following approach was made: the lidar signals are detected simultaneously in analog and in photoncounting mode. As the intensities of our rotational Raman signals are too strong, the photon-counting signals are affected by dead-time effects in lower heights of about $6 \mathrm{~km}$ in daytime. Correction of these dead-time effects (Behrendt et al., 2004) is possible down to about $1.5 \mathrm{~km}$. As this height limit is still too high for CBL studies, the analog signals have been used for the measurements of this study. In order to derive the shot-noise errors of the measurements with Poisson statistics, the analog signals of each $10 \mathrm{~s}$ profile were fitted to 


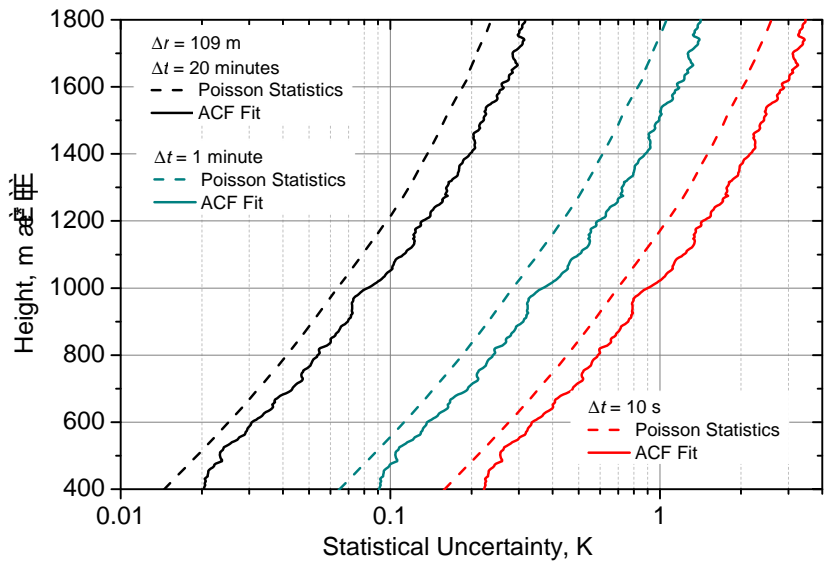

Figure 7. Statistical uncertainties of $10 \mathrm{~s}, 1 \mathrm{~min}$, and $20 \mathrm{~min}$ temperature profiles at noontime determined with a $2 / 3$-power-law fit of the ACF data (see Fig. 6). Shot-noise errors calculated by use of Poisson statistics from the detected signal intensities in each height are shown for comparison. It can be seen that the statistical uncertainty of the RRL temperature measurements is mainly governed by shot noise. The range resolution of the data was $109 \mathrm{~m}$.

the photon-counting signals in heights between about 1.5 and $3 \mathrm{~km}$, where both detection techniques were providing reliable data after dead-time correction of the photon-counting data. By this scaling, photon-counting rates could then be attributed to the analog signal intensities in lower altitudes. These attributed count rates were consequently used. The background photon-counting numbers were derived from the photon-counting signals detected from high altitudes.

The ratio of the two background-corrected photon-count numbers $N_{\mathrm{RR} 1}$ and $N_{\mathrm{RR} 2}$ of lower and higher rotational quantum number transition channels

$Q=\frac{N_{\mathrm{RR} 2}}{N_{\mathrm{RR} 1}}$

is the measurement parameter which yields the atmospheric temperature profile after calibration of the system.

The shot-noise error of a signal with $N$ photon counts according to Poisson statistics is

$\Delta N(z)=\sqrt{N(z)}$.

Error propagation for the RRL temperature data then yields (Behrendt et al., 2002)

$$
\begin{aligned}
& \Delta T(z)=\frac{\partial T}{\partial Q} \frac{N_{\mathrm{RR} 2}(z)}{N_{\mathrm{RR} 1}(z)} \\
& \sqrt{\frac{N_{\mathrm{RR} 1}^{*}(z)+\left(\Delta \bar{B}_{\mathrm{RR} 1)^{2}}\right.}{\left(N_{\mathrm{RR} 1}(z)\right)^{2}}+\frac{N_{\mathrm{RR} 2}^{*}(z)+\left(\Delta \bar{B}_{\mathrm{RR} 2}\right)^{2}}{\left(N_{\mathrm{RR} 2}(z)\right)^{2}}},
\end{aligned}
$$

with $N_{\mathrm{RR} 1}^{*}(z)$ and $N_{\mathrm{RR} 2}^{*}(z)$ for the photon counts in the two rotational Raman channels before background correction. $N_{\mathrm{RR} i}(z)=N_{\mathrm{RR} i}^{*}(z)-\bar{B}_{\mathrm{RR} i}$ with $i=1,2$ are the signals which are corrected for background noise per range bin $\bar{B}_{\mathrm{RR} i} . \partial T / \partial Q$ is provided by the temperature calibration function. As outlined already above (see Sect. 3.1), the uncertainty of this calibration for the analysis of turbulent temperature fluctuations is negligible.

Since the background is determined over many range bins, the statistical uncertainty of the background can be neglected (Behrendt et al., 2004) so that one finally gets

$$
\begin{aligned}
& \Delta T(z)=\frac{\partial T}{\partial Q} \frac{N_{\mathrm{RR} 2}(z)}{N_{\mathrm{RR} 1}(z)} \\
& \sqrt{\frac{N_{\mathrm{RR} 1}(z)+\bar{B}_{\mathrm{RR} 1}}{\left(N_{\mathrm{RR} 1}(z)\right)^{2}}+\frac{N_{\mathrm{RR} 2}(z)+\bar{B}_{\mathrm{RR} 2}}{\left(N_{\mathrm{RR} 2}(z)\right)^{2}} .}
\end{aligned}
$$

The data in Fig. 7 show that the shot-noise errors calculated with Poisson statistics provide lower estimates for the total errors. But the comparison also confirms that the photon shot noise gives the major contribution (about $75 \%$ ) and that other statistical error sources (like the electric noise of the analog signals) are comparatively small. A similar result, also for analog signals which were glued to photon-counting signals, has already been obtained before for water vapor Raman lidar by Whiteman et al. (2006).

The background-corrected rotational Raman signals scale according to

$N_{\mathrm{RR} i}(z) \propto P \Delta t \Delta z \eta_{\mathrm{t}} \eta_{\mathrm{r}} A$,

where $i=1,2, P$ is laser power, $\Delta t$ is measurement time, $\Delta z$ is range resolution, $\eta_{\mathrm{t}}$ and $\eta_{\mathrm{r}}$ are transmitter and receiver efficiency, respectively, and $A$ is receiving telescope area. The background counts in each signal range bin scale in a similar way but without being influenced by power $P$ and $\eta_{\mathrm{t}}$, so that we get

$\bar{B}_{\mathrm{RR} i}(z) \propto \Delta t \Delta z \eta_{\mathrm{r}} A$.

One can see from Eqs. (7) to (9) that the statistical measurement uncertainty scales consequently with the parameters which are found in both previous equations according to

$$
\Delta T \propto \frac{1}{\sqrt{\Delta t \Delta z \eta_{\mathrm{r}} A}} .
$$

It is noteworthy, that increases of the laser power $P$ and transmitter efficiency $\eta_{\mathrm{t}}$ are even more effective in reducing $\Delta T$ than increases of $\Delta t, \Delta z, \eta_{\mathrm{r}}$, or $A$ because the former improve only the backscatter signals and do not increase the background simultaneously like the latter. The value of the improvement obtained from increases of $P$ or $\eta_{\mathrm{t}}$, however, depends on the intensity of the background and thus on height and background-light conditions (see also Radlach et al., 2008; Hammann et al., 2015).

The statistical uncertainties for the RRL temperature measurements at noontime shown in Fig. 7 were determined with $10 \mathrm{~s}$ temporal resolution and for range averaging of 


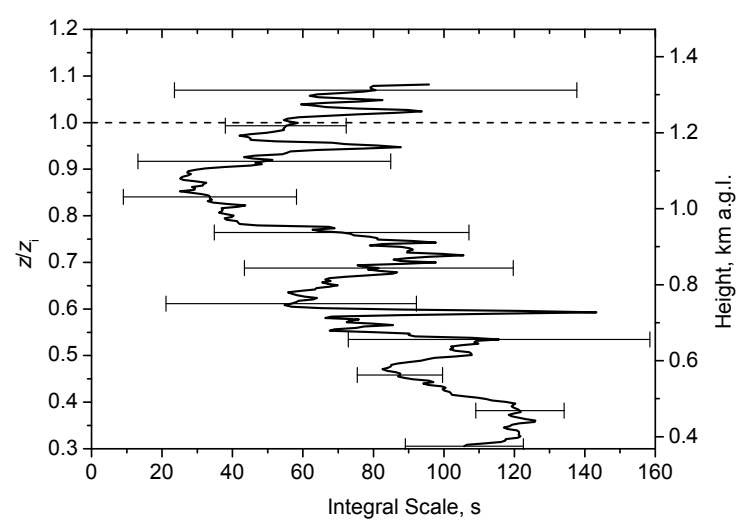

Figure 8. Integral scale of the temperature fluctuations shown in Fig. 5 ( $1 \mathrm{~h}$ period between 11:00 and 12:00 UTC, 24 April 2013). Error bars show the noise errors. The mean CBL height $z_{i}$ of $1230 \mathrm{~m}$ (dashed line) was determined with the Haar-wavelet analysis of $\beta_{\text {par }}$ and was used for the relative height scale $z / z_{i}$.

$109 \mathrm{~m}$. The resulting error profiles for other temporal resolutions were then derived from the $10 \mathrm{~s}$ error profile by use of Eq. (10). The errors for other range resolutions can be easily obtained from Eq. (10) in a similar way.

The results of the error analysis show the very high performance of the UHOH RRL temperature data: with 10 s resolution, the total statistical uncertainty $\Delta T$ at noontime determined from the variance analysis of the temperature fluctuations is below $1 \mathrm{~K}$ up to $1020 \mathrm{~m}$ a.g.l. With $1 \mathrm{~min}$ resolution, $\Delta T$ is below $0.4 \mathrm{~K}$ up to $1000 \mathrm{~m}$ a.g.l. and below $1 \mathrm{~K}$ up to $1510 \mathrm{~m}$ a.g.l. With $20 \mathrm{~min}$ averaging, $\Delta T$ is below 0.1 and $0.3 \mathrm{~K}$ up to 1050 and $1710 \mathrm{~m}$ a.g.l., respectively.

\subsection{Integral scale}

Figure 8 shows the profile of the integral scale of the temperature fluctuations. It was obtained with the 2/3-power-law fit of the structure function to the ACF (Lenschow et al., 2000; Wulfmeyer et al., 2010). The integral scale is about $80 \mathrm{~s}$ in the mixed layer decreasing towards smaller values in the IL. At $z_{i}$, the integral scale was $(56 \pm 17) \mathrm{s}$. The integral scale is significantly larger than the temporal resolution of the UHOH RRL data of $10 \mathrm{~s}$. This confirms that the resolution of our data is high enough to resolve the turbulent temperature fluctuations including the major part of the inertial subrange throughout the CBL. The integral timescale, which can be related to a length scale provided that the mean horizontal wind speed is known, is considered as a measure of the mean size of the turbulent eddies involved in the boundary layer mixing processes.

\subsection{Temperature variance}

To the best of our knowledge, the first profile of the temperature variance of the atmosphere $\overline{\left(T_{\mathrm{a}}^{\prime}(z)\right)^{2}}$ measured with

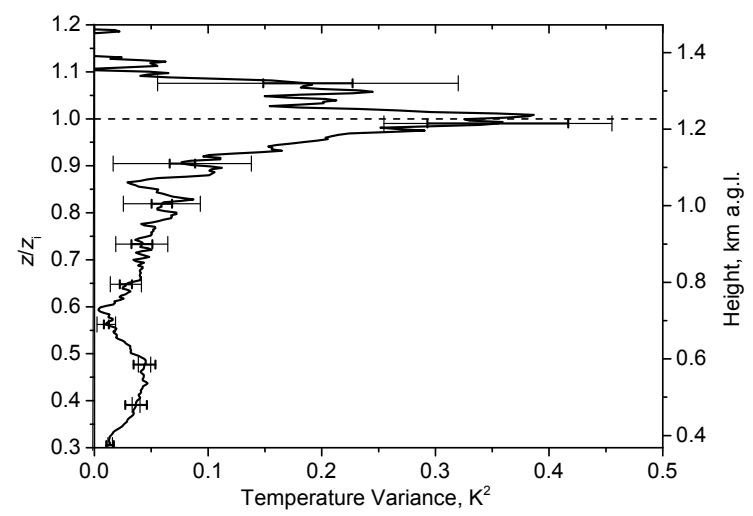

Figure 9. Profile of temperature variance $(1 \mathrm{~h}$ period between 11:00 and 12:00 UTC, 24 April 2013). Error bars show the noise errors (thin error bars) and the sampling errors (thick error bars). The mean CBL height $z_{i}$ of $1230 \mathrm{~m}$ (dashed line) was used for the relative height scale $z / z_{i}$.

a lidar system is shown in Fig. 9; the profile starts at about $0.3 z_{i}$ and covers the whole CBL. We found that between 0.3 and $0.9 z_{i}$, i.e., the major part of the CBL, the atmospheric variance was much smaller than in the IL. Here the values were only up to $0.1 \mathrm{~K}^{2}$ (at $1100 \mathrm{~m}=0.9 z_{i}$ with 0.01 and $0.06 \mathrm{~K}^{2}$ for the sampling and noise error, respectively). We also used the methods of Lenschow et al. (2000) for deriving these errors. While the noise errors denote the $1 \sigma$ statistical uncertainties of the data product due to uncorrelated noise in the time series of the input data, the sampling errors describe those uncertainties resulting from the limited number of atmospheric eddies in the analysis period. Taking the error bars into account, one finds that the apparent minimum of the temperature variance profile at $0.6 z_{i}$ is only weakly significant. What remains is a profile with slightly increasing variance with height in the CBL and a clear maximum in the IL close to $z_{i}$. This maximum of the variance profile was $0.39 \mathrm{~K}^{2}$ with a sampling error of 0.07 and $0.11 \mathrm{~K}^{2}$ for the noise error (root-mean-square variability). Above, the variance decreased again. One expects such a structure for the variance profile: except at the surface, the temperature variance in the CBL is largest in the $\mathrm{IL}$, since the temporal variability is driven by entrainment caused by turbulent buoyancy-driven motions acting against the temperature inversion at the top of the CBL (e.g., Deardorff, 1974; André et al., 1978; Stull, 1988; Moeng and Wyngaard, 1989).

For quantitative comparisons, often normalization of the temperature variance profile with $T^{*}$ is used (Deardorff, 1970). But in the real world with its heterogeneous land use and soil properties and thus corresponding flux variability such scaling becomes difficult. Instead of a single scaling value, one could employ several flux stations and try to find a more representative scaling parameter by weighted averaging of the measurements made over different land-use types. But even then one expects that the scaled temperature vari- 
ance profile depends on the ratio of the mean entrainment and surface flux (e.g., Moeng and Wyngaard, 1989). Thus, we decided not to scale the variance profile here and leave further generalizations to future studies based on more cases.

\subsection{Third-order moment and skewness}

The third-order moment (TOM) of a fluctuation is a measure of the asymmetry of the distribution. The skewness $S$ is the TOM normalized by the variance to a dimensionless parameter defined for temperature as

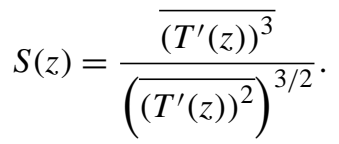

The normal distribution (Gaussian curve) has zero TOM and $S$. Positive values for TOM and $S$ show a right-skewed distribution where the mode is smaller than the mean. If the mode is larger than the mean, TOM and $S$ become negative (left-skewed distribution).

TOM and $S$ profiles for the atmospheric temperature fluctuations of our case were derived with the technique of Lenschow et al. (2000), as explained in Sect. 3.2. The results are shown in Fig. 10. Up to about $0.9 z_{i}$, the TOM was not different to zero (taking the $1 \sigma$ statistical uncertainties into account). In the IL, i.e., between 0.9 and $1.1 z_{i}$, a negative peak is found with values down to $-0.93 \mathrm{~K}^{3}$ with 0.05 and $0.16 \mathrm{~K}^{3}$ for the sampling and noise errors, respectively. The skewness profile shows the same characteristics. Only data around $0.6 z_{i}$ had to be omitted from the skewness profile because the measured variance values are close to zero here and thus dividing by these values yields too large relative errors. At $z_{i}$, we found a skewness of -4.1 with 1.1 and 1.9 for the sampling and noise errors, respectively.

TOM and $S$ profiles reveal interesting characteristics of the thermal plumes which were present in the CBL in this case. As rising plumes of warmer air are typically narrow and surrounded by larger areas of air close to the average temperature, one expects slightly positive temperature skewness in the major part of the CBL; e.g., Mironov et al. (1999) show values between 0 and 2 (see their Fig. 1b); they did not show negative values which would indicate narrow cold plumes. In the CBL up to about $0.9 z_{i}$, the measured values in our case agree with these data taking the uncertainties into account.

The negative minima of TOM and $S$ in the IL above show a clear difference between the IL and the CBL below. Between 0.9 and $1.1 z_{i}$, negative and positive fluctuations were not symmetric but fewer very cold fluctuations were balanced by many warm fluctuations with less difference to the mean.

Because turbulent mixing occurs in the IL in a region of positive vertical temperature gradient, the air present in the free troposphere is warmer than the air in the CBL below. Consequently, the negative peak indicates that the cold overshooting updrafts in the IL were narrower in time than the downdrafts of warmer air.
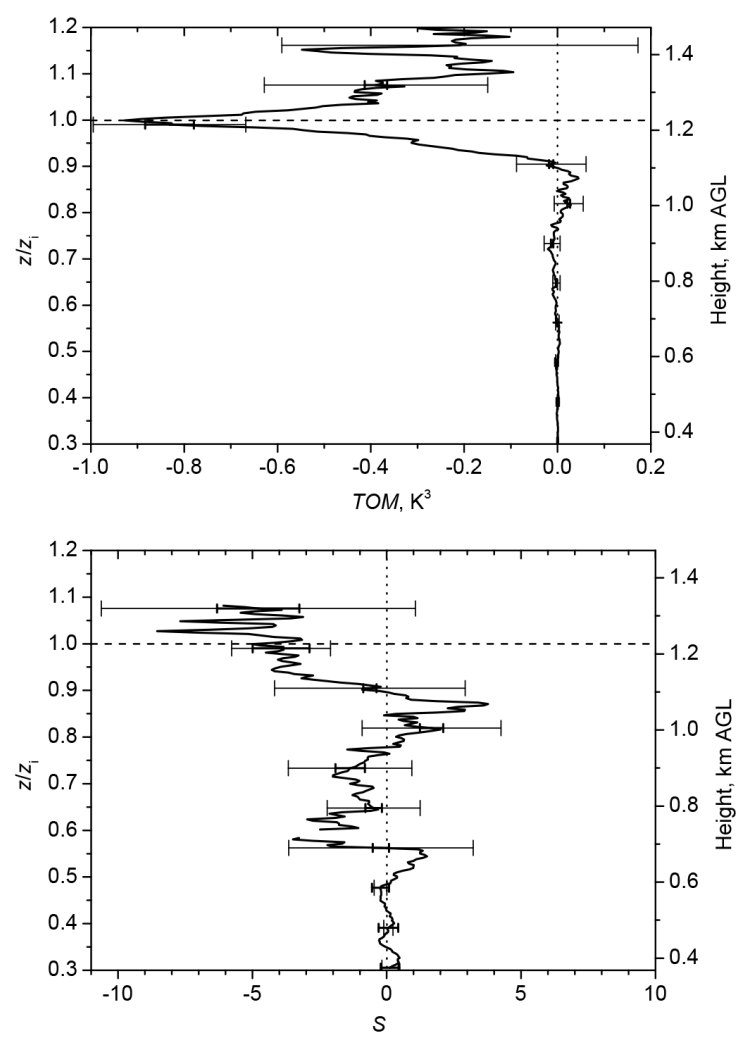

Figure 10. Same as Fig. 9 but profiles of the third-order moment (TOM) and the skewness $S$. Error bars show the noise errors (thin error bars) and the sampling errors (thick error bars). The mean CBL height $z_{i}$ of $1230 \mathrm{~m}$ (dashed line) was used for the relative height scale $z / z_{i}$. The dotted vertical line marks zero skewness. Skewness data around 0.6 and above $1.1 z / z_{i}$ were omitted because the data were too noisy here due to variances close to zero.

Similar characteristics of the temperature TOM and skewness profiles in the IL were discussed, e.g., by Mironov et al. (1999), Canuto et al. (2001), and Cheng et al. (2005) who compare experimental data (tank, wind tunnel, airborne in situ), large eddy simulation (LES) data, and analytical expressions. Now, more comparisons can be performed between real atmospheric measurements and models.

Interestingly, an inverse structure of the TOM profile is found with respect to humidity fluctuations (Wulfmeyer, 1999b; Wulfmeyer et al., 2010; Turner et al., 2014b). Combining these results, it should be possible to perform very detailed comparisons with LES and to refine turbulence parameterizations. This concerns particularly the TKE (turbulent kinetic energy) 3.0 order schemes that are using the closure of the variance budget for determining the turbulent exchange coefficients.

\subsection{Fourth-order moment and kurtosis}

The fourth-order moment (FOM) is a measure of the steepness at the sides of the distribution and the corresponding 
flatness of the peak. The kurtosis is the FOM normalized by the variance to a dimensionless parameter according to

$\operatorname{Kurtosis}(z)=\frac{\overline{\left(T^{\prime}(z)\right)^{4}}}{\left(\overline{\left.\left(T^{\prime}(z)\right)^{2}\right)^{2}} .\right.}$

With this definition, the normal distribution (Gauss curve) has a kurtosis of 3. Equation (12) is also used by Lenschow et al. (2000); we follow this definition here. Please note that sometimes kurtosis is defined differently including a subtraction of 3 which then results in a kurtosis of 0 for the normal distribution, but mostly Kurtosis -3 is called "excess kurtosis".

Figure 11 shows FOM and kurtosis profiles of the measured temperature fluctuations of our case which have also been obtained with the method of Lenschow et al. (2000) for noise correction. For both FOM and kurtosis, the noise errors of the data are quite large; the importance of an error analysis becomes once more obvious. Throughout the CBL, no significant differences to the normal distribution are found. While the values for the FOM are close to zero in the CBL $\left(<0.5 \mathrm{~K}^{4}\right.$ up to $0.9 z_{i}$ ), they appear larger in the IL, but the noise error does not allow for determining exact values, zero is still within the $1 \sigma$ noise error bars. At $z_{i}$, FOM was $3.0 \mathrm{~K}^{4}$ with 0.1 and $4.2 \mathrm{~K}^{4}$ for the sampling and noise errors, respectively. The kurtosis at $z_{i}$ was 23 with 8 and 35 for the sampling and noise errors, respectively. We conclude that the distribution of atmospheric temperature fluctuations was not significantly different to a Gaussian distribution (quasi-normal) regarding its fourth-order moment and kurtosis in our case.

Even if the data here are too noisy to identify non-zero FOM or kurtosis in the IL, it is interesting to note that higher values of kurtosis in the IL would reflect a situation for which a large fraction of the temperature fluctuations occurring in this region would exist due to infrequent, very large deviations in temperature; the related most vigorous thermals would then be capable to yield quite extreme temperature fluctuations, while mixing intensively in the IL with the air of the lower free troposphere. In contrast to this, the temperature fluctuations would be more moderate (Gaussian) in the CBL below.

\section{Conclusions}

We have shown that rotational Raman lidar provides a remote-sensing technique for the analysis of the turbulent temperature fluctuations within the well-developed CBL during noontime - even though the background-light conditions at noon are least favorable for the measurements. The required high temporal and spatial resolution combined with low-enough statistical noise of the measured data is reached by the UHOH RRL which is to the best of our knowledge for the first time. The data can thus be evaluated during all
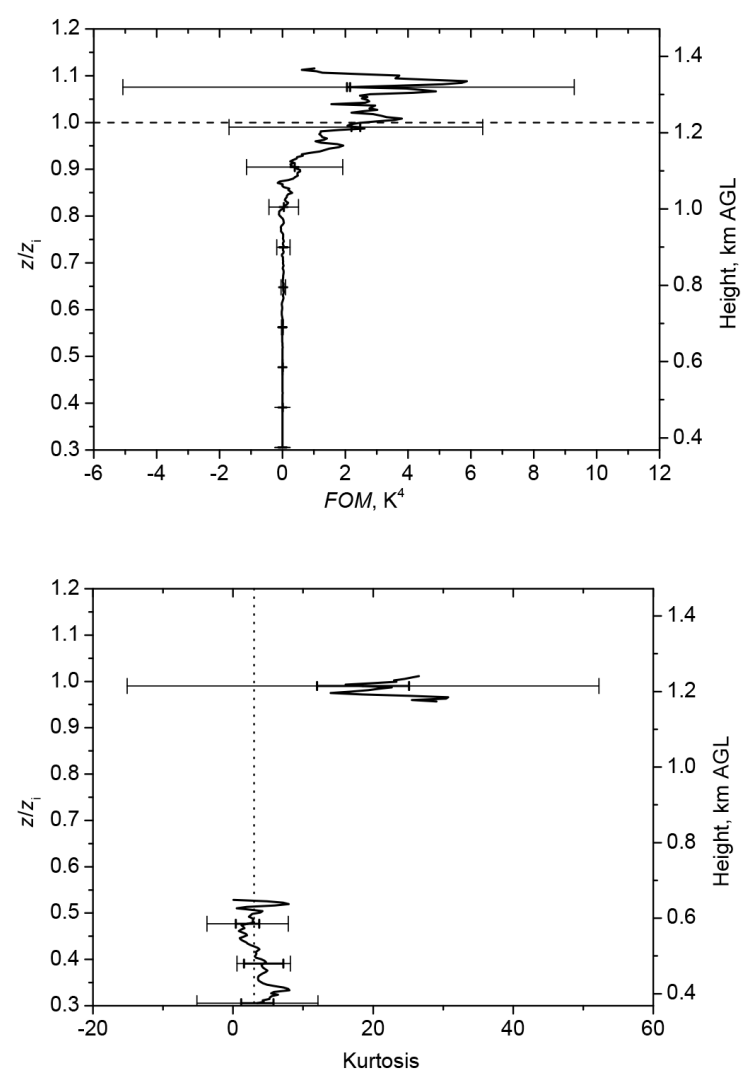

Figure 11. Same as Fig. 9 but profiles of the fourth-order moment (FOM) and kurtosis. Only kurtosis data below 0.55 and around 1.0 $z / z_{i}$ are shown because other data are too noisy. The dotted vertical line in the lower panel marks a value of 3 which is the kurtosis of the normal distribution. Error bars show the noise errors (thin error bars) and the sampling errors (thick error bars). The mean CBL height $z_{i}$ of $1230 \mathrm{~m}$ (dashed line in the upper panel) was used for the relative height scale $z / z_{i}$.

time periods of the day for studying the structure of the atmospheric boundary layer - of course also at night.

A case of the HOPE campaign was analyzed. The data were collected between 11:00 and 12:00 UTC on IOP 6, 24 April 2013, i.e., exactly around local noon (11:33 UTC). The UHOH RRL was located near the village of Hambach in western Germany $\left(50^{\circ} 53^{\prime} 50.56^{\prime \prime} \mathrm{N}, 6^{\circ} 27^{\prime} 50.39^{\prime \prime} \mathrm{E}\right.$; $110 \mathrm{~m}$ a.s.l.).

A profile of the noise variance was used to estimate the statistical uncertainty $\Delta T$ of the temperature data with a structure function fit to the ACF. A comparison with a $\Delta T$ profile derived with Poisson statistics demonstrated that the statistical error is mainly due to shot noise. The Haar-wavelet technique was applied to $10 \mathrm{~s}$ profiles of $\beta_{\text {par }}$ and provided the mean CBL height over the observation period of $z_{i}=$ $1230 \mathrm{~m}$ a.g.l. This value was used for normalizing the height scale. The integral scale had a mean of about $80 \mathrm{~s}$ in the CBL confirming that the temporal resolution of the RRL data of 
$10 \mathrm{~s}$ was sufficient for resolving the majority of turbulence down to the inertial subrange.

The results of this study give further information on turbulent temperature fluctuations and their statistics in the CBL and within the IL.

The atmospheric variance profile showed clearly the largest values close to $z_{i}$. A maximum of the variance of the atmospheric temperature fluctuations was found in the IL: $0.39 \mathrm{~K}^{2}$ with a sampling and noise error of 0.07 and $0.11 \mathrm{~K}^{2}$, respectively.

Subsequently, also profiles of the third- and fourth-order moments were derived:

TOM and skewness were not significantly different to zero within the CBL up to about $0.9 z_{i}$. In the IL between 0.9 and $1.1 z_{i}$, a negative minimum was found with values down to $-0.93 \mathrm{~K}^{3}$ with 0.05 and $0.16 \mathrm{~K}^{3}$ for the sampling and noise errors, respectively. Skewness at $z_{i}$ was -4.1 and with 1.1 and 1.9 for the sampling and noise errors, respectively. We conclude that the turbulent temperature fluctuations were not significantly skewed in the CBL. In contrast to this, the atmospheric temperature fluctuations in the IL were clearly skewed to the left (negative skewness). This finding is related to narrower cold overshooting updrafts and broader downward mixing of warmer air from the free troposphere in the IL.

Throughout the CBL, no significant differences to the normal distribution were found for FOM and the kurtosis. For all moments but especially the FOM, the importance of an error analysis became once more obvious.

A quasi-normal FOM even when TOM is non-zero, agrees with the hypothesis of Millionshchikov (1941) which forms the basis for a large number of closure models (see Gryanik et al., 2005, for an overview). However, some recent theoretical studies, measurement data, and LES data suggest that this hypothesis would not be valid for temperature in the CBL (also see Gryanik et al., 2005, for an overview). Gryanik and Hartmann (2002) suggested furthermore a parameterization between the FOM, skewness, and variance of turbulent temperature fluctuations which can be tested as soon as a larger number of measurement cases on turbulent temperature fluctuations with rotational Raman lidar have become available.

It is planned to extend the investigation of CBL characteristics in future studies also by combining the UHOH RRL data with humidity and wind observations from water vapor DIAL (Behrendt et al., 2009; Wagner et al., 2013; Muppa et al., 2015) and Doppler lidar. Furthermore, also the scanning capability of the UHOH RRL will be used in the future to collect data closer to the ground and even the surface layer (Behrendt et al., 2012) in order to investigate heterogeneities over different terrain.

The combination of different turbulent parameters measured by lidar - preferably, at the same atmospheric coordinates simultaneously - promises to provide further understanding on the important processes taking place in the CBL including the IL. For instance, up until now, the key phys- ical processes governing the IL and their relationships with other CBL properties unfortunately remain only poorly understood: they are oversimplified in empirical studies and poorly represented in the models. In consequence, more data should be evaluated to get the statistics of the turbulent temperature fluctuations under a variety of atmospheric conditions. We believe that corresponding measurements with RRL will contribute significantly to better understanding of boundary layer meteorology in the future - not only in daytime but also at night so that the entire diurnal cycle is covered and the characteristics of turbulent temperature fluctuations in different stability regimes can be observed.

Acknowledgements. The HOPE campaign was funded by the German Research Ministry under the project number 01LK1212 A. We thank the colleagues of Karlsruhe Institute of Technology (KIT) and the University of Cologne for performing the radiosonde launches. Furthermore, we like to thank the three anonymous reviewers for their helpful comments.

Edited by: S. Buehler

\section{References}

André, J. C., De Moor, G., Lacarrère, P., Therry, G., and Du Vachat, R.: Modeling the 24-hour evolution of the mean and turbulent structures of the planetary boundary layer, J. Atmos. Sci., 35, 1861-1883, 1978.

Angevine, W. M., Doviak, R. J., and Sorbjan, Z. S.: Remote Sensing of Vertical Velocity Variance and Surface Heat Flux in a Convective Boundary Layer, J. Appl. Meteorol. 33, 977-983, 1994.

Behrendt, A.: Temperature measurements with lidar, in: Lidar: Range-Resolved Optical Remote Sensing of the Atmosphere, edited by: Weitkamp, C., Springer, New York, 273-305, 2005.

Behrendt, A. and Reichardt, J.: Atmospheric temperature profiling in the presence of clouds with a pure rotational Raman lidar by use of an interference-filter-based polychromator, Appl. Optics, 39, 1372-1378, 2000.

Behrendt, A., Nakamura, T., Onishi, M., Baumgart, R., and Tsuda, T.: Combined Raman lidar for the measurement of atmospheric temperature, water vapor, particle extinction coefficient, and particle backscatter coefficient, Appl. Optics, 41, 7657-7666, 2002.

Behrendt, A., Nakamura, T., and Tsuda, T.: Combined temperature lidar for measurements in the troposphere, stratosphere, and mesosphere, Appl. Optics, 43, 2930-2939, 2004.

Behrendt, A., Wulfmeyer, V., Riede, A., Wagner, G., Pal, S., Bauer, H., Radlach, M., and Späth, F.: 3-Dimensional observations of atmospheric humidity with a scanning differential absorption lidar, in: Remote Sensing of Clouds and the Atmosphere XIV, edited by: Picard, R. H., Schäfer, K., Comeron, A., and van Weele, M., SPIE Conference Proceeding Vol. 7475, ISBN: 9780819477804, 2009, Art. No. 74750L, doi:10.1117/12.835143, 2009.

Behrendt, A., Pal, S., Aoshima, F., Bender, M., Blyth, A., Corsmeier, U., Cuesta, J., Dick, G., Dorninger, M., Flamant, C., Di Girolamo, P., Gorgas, T., Huang, Y., Kalthoff, N., 
Khodayar, S., Mannstein, H., Träumner, K., Wieser, A., and Wulfmeyer, V.: Observation of convection initiation processes with a suite of state-of-the-art research instruments during COPS IOP8b, Q. J. Roy. Meteor. Soc., 137, 81-100, doi:10.1002/qj.758, 2011a.

Behrendt, A., Pal, S., Wulfmeyer, V., Valdebenito B., Á. M., and Lammel, G.: A novel approach for the char-acterisation of transport and optical properties of aerosol particles near sources, Part I: measurement of particle backscatter coefficient maps with a scanning UV lidar, Atmos. Environ., 45, 2795-2802, doi:10.1016/j.atmosenv.2011.02.061, 2011b.

Behrendt, A., Hammann, E., Späth, F., Riede, A., Metzendorf, S., and Wulfmeyer, V.: Revealing surface layer heterogeneities wit scanning water vapor DIAL and scanning rotational Raman lidar, in: Reviewed and Revised Papers Presented at the 26th International Laser Radar Conference (ILRC 2012), 25-29 June 2012, Porto Heli, Greece, edited by: Papayannis, A., Balis, D., and Amiridis, V., paper S7P-17, 913-916, 2012.

Campistron, B., Bernard, S., Bénech, B., Ardhuin-Girard, F., Dessens, J., Dupont, E., and Carissimo, B.: Turbulent Dissipation Rate In The Boundary Layer Via Uhf Wind Profiler Doppler Spectral Width Measurements, Bound.-Lay. Meteorol., 103, 361-389, 2002.

Canuto, V. M., Chang, Y., and Howard, A.: New third-order moments for the convective boundary layer, J. Atmos. Sci., 58, 1169-1172, 2001.

Cheng, Y., Canuto, V. M., and Howard, A. M.: Nonlocal convective PBL Model based on new third- and fourth-order moments, J. Atmos. Sci., 62, 2189-2204, 2005.

Clarke, R. H., Dyer, A. J., Brook, R. R., Reid, D. G., and Troup, A. J.: The Wangara experiment: Boundary layer data. Tech. Paper No. 19, CSIRO, Division of Meteorological Physics, Aspendale, Australia, 362 pp., 1971.

Cooney, J.: Measurement of atmospheric temperature profiles by Raman backscatter, J. Appl. Meteorol., 11, 108-112, 1972.

Corsmeier, U., Kalthoff, N., Barthlott, Ch., Behrendt, A., Di Girolamo, P., Dorninger, M., Aoshima, F., Handwerker, J., Kottmeier, C., Mahlke, H., Mobbs, S., Vaughan, G., Wickert, J., and Wulfmeyer, V.: Driving processes for deep convection over complex terrain: a multiscale analysis of observations from COPS-IOP 9c, Q. J. Roy. Meteor. Soc., 137, 137-155, doi:10.1002/qj.754, 2011.

Deardorff, J. W.: Convective velocity and temperature scales for the unstable planetary boundary layer and for Rayleigh convection, J. Atmos. Sci., 27, 1211-1213, 1970.

Deardorff, J. W.: Three-dimensional numerical study of turbulence in an entraining mixed layer, Bound.-Lay. Meteorol., 7, 199-226, 1974.

Di Girolamo, P., Marchese, R., Whiteman, D. N., and Demoz, B.: Rotational Raman lidar measurements of atmospheric temperature in the UV, Geophys. Res. Lett., 31, L01106, doi:10.1029/2003GL018342, 2004.

Di Girolamo, P., Behrendt, A., and Wulfmeyer, V.: Spaceborne profiling of atmospheric temperature and particle extinction with pure rotational Raman lidar and of relative humidity in combination with differential absorption lidar: performance simulations, Appl. Optics, 45, 2474-2494, 2006.
Eng, K., Coulter, R., and Brutsaert, W.: Vertical Velocity Variance in the Mixed Layer from Radar Wind Profilers, J. Hydrol. Eng., 8, 301-307, 2003.

Furumoto, J. and Tsuda, T.: Characteristics of energy dissipation rate and effect of humidity on turbulence echo power revealed by MU radar-RASS Measurements, J. Atmos. Terr. Sol.-Phy., 63, 285-294, 2001.

Giez, A., Ehret, G., Schwiesow, R. L., Davis, K. J., and Lenschow, D. H.: Water vapor flux measurements from groundbased vertically pointed water vapor differential absorption and Doppler lidars, J. Atmos. Ocean. Tech., 16, 237-250, 1999.

Groenemeijer, P., Barthlott, C., Behrendt, A., Corsmeier, U., Handwerker, J., Kohler, M., Kottmeier, C., Mahlke, H., Pal, S., Radlach, M., Trentmann, J., Wieser, A., and Wulfmeyer, V.: Multi-sensor measurements of a convective storm cluster over a low mountain range: adaptive observations during PRINCE, Mon. Weather Rev., 137, 585-602, doi:10.1175/2008MWR2562.1, 2009.

Gryanik, V. M. and Hartmann, J.: A turbulence closure for the convective boundary layer based on a two-scale mass-flux approach, J. Atmos. Sci., 59, 2729-2744, 2002.

Gryanik, V. M., Hartmann, J., Raasch, S., and Schröter, M.: A refinement of the Millionshchikov Quasi-Normality Hypothesis for convective boundary layer turbulence, J. Atmos. Sci., 62, 26322638, 2005.

Hammann, E., Behrendt, A., Le Mounier, F., and Wulfmeyer, V.: Temperature profiling of the atmospheric boundary layer with rotational Raman lidar during the $\mathrm{HD}(\mathrm{CP})^{2}$ Observational Prototype Experiment, Atmos. Chem. Phys., 15, 2867-2881, doi:10.5194/acp-15-2867-2015, 2015.

Hermawan, E. and Tsuda, T.: Estimation of turbulence energy dissipation rate and vertical eddy diffusivity with the MU radar RASS, J. Atmos. Sol.-Terr. Phy., 61, 1123-1130, doi:10.1016/S1364-6826(99)00075-9, 1999.

Kadygrov, E. N., Shur, G. N., and Viazankin, A. S.: Investigation of atmospheric boundary layer temperature, turbulence, and wind parameters on the basis of passive microwave remote sensing, Radio Sci., 38, 8048, doi:10.1029/2002RS002647, 2003.

Kalthoff, N., Träumner, K., Adler, B., Späth, S., Behrendt, A., Wieser, A., Handwerker, J., Madonna, F., and Wulfmeyer, V.: Dry and moist convection in the boundary layer over the Black Forest - a combined analysis of in situ and remote sensing data, Meteorol. Z., 22, 445-461, doi:10.1127/0941-2948/2013/0417, 2013.

Kiemle, C., Ehret, G., Giez, A., Davis, K. J., Lenschow, D. H., and Oncley, S. P.: Estimation of boundary layer humidity fluxes and statistics from airborne differential absorption lidar (DIAL), J. Geophys Res., 102, 29189-29203, 1997.

Kiemle, C., Brewer, W. A., Ehret, G., Hardesty, R. M., Fix, A., Senff, C., Wirth, M., Poberaj, G., and LeMone, M. A.: Latent heat flux profiles from collocated airborne water vapor and wind lidars during IHOP 2002, J. Atmos. Ocean. Tech., 24, 627-639, 2007.

Kiemle, C., Wirth, M., Fix, A., Rahm, S., Corsmeier, U., and Di Girolamo, P.: Latent heat fluxes over complex terrain from airborne water vapour and wind lidars, Q. J. Roy. Meteor. Soc., 137, 190-203, 2011.

Kolmogorov, A. N.: The Local Structure of Turbulence in Incompressible Viscous Fluid for Very Large Reynolds Numbers, Proc. 
R. Soc. Lond., A 434, 1890, 9-13, doi:10.1098/rspa.1991.0075, 1991.

Lenschow, D. H., Wulfmeyer, V., and Senff, C.: Measuring second through fourth-order moments in noisy data, J. Atmos. Ocean. Tech., 17, 1330-1347, 2000.

Lenschow, D. H., Lothon, M., Mayor, S. D., Sullivan, P. P., and Caunt, G.: A comparison of higher-order vertical velocity statistics in the convective boundary layer from lidar with in-situ measurements and large-eddy simulations, Bound.-Lay. Meteorol., $143,107-123,2012$.

Martin, S., Bange, J., and Beyrich, F.: Meteorological profiling of the lower troposphere using the research UAV " $\mathrm{M}^{2} \mathrm{AV}$ Carolo", Atmos. Meas. Tech., 4, 705-716, doi:10.5194/amt-4-705-2011, 2011.

Martin, S., Beyrich, F., and Bange, J.: Observing Entrainment Processes Using a Small Unmanned Aerial Vehicle: A Feasibility Study, Bound.-Lay. Meteorol., 150, 449-467, 2014.

Millionshchikov, M. D.: On the Theory of Homogeneous Isotropic Turbulence, Dokl. Akad. Nauk SSSR, 32, 611-614, 1941.

Mironov, D. V., Gryanik, M., Lykossov, V. N., and Zilitinkevich, S. S.: Comments on "A new second-order turbulence closure scheme for the planetary boundary layer", J. Atmos. Sci., 56, 3478-3481, 1999.

Moeng, C.-H. and Wyngaard, J. C.: Evaluation of turbulent transport and dissipation closures in second-order modelling, J. Atmos. Sci., 46, 2311-2330, 1989.

Muppa, S. K., Behrendt, A., Späth, F., Wulfmeyer, V., Metzendorf, S., and Riede, A.: Turbulent humidity fluctuations in the convective boundary layer: Case studies using DIAL measurements, Bound.-Lay. Meteorol., under review, 2015.

Muschinski, A., Frehlich, R., Jensen, M., Hugo, R., Eaton, F., and Balsley, B.: Fine-scale measurements of turbulence in the lower troposphere: an intercomparison between a kite- and balloonborne, and a helicopter-borne measurement system, Bound.-Lay. Meteorol., 98, 219-250, 2001.

Nash, J., Oakley, T., Vömel, H., and Li, W.: WMO Intercomparison of High Quality Radiosonde Systems, Published by the World Meteorological Organization (WMO), WMO/TD-No. 1580; Instruments and Observing Methods Report No. 107, 249 pp., 2011.

O’Connor, E., Illingworth, A., Brooks, I., Westbrook, M., Christopher, D., Hogan, R., Davies, F., and Brooks, B.: A Method for Estimating the Turbulent Kinetic Energy Dissipation Rate from a Vertically Pointing Doppler Lidar, and Independent Evaluation from Balloon-Borne In Situ Measurements, J. Atmos. Ocean. Tech., 27, 1652-1664, doi:10.1175/2010JTECHA1455.1, 2010.

Pal, S., Behrendt, A., and Wulfmeyer, V.: Elastic-backscatter-lidarbased characterization of the convective boundary layer and investigation of related statistics, Ann. Geophys., 28, 825-847, doi:10.5194/angeo-28-825-2010, 2010.

Pal, S., Xueref-Remy, I., Ammoura, L., Chazette, P., Gibert, F., Royer, P., Dieudonné, E., Dupont, J. C., Haeffelin, M., Lac, C., Lopez, M., Morille, Y., and Ravetta, F.: Spatio-temporal variability of the atmospheric boundary layer depth over the Paris agglomeration: an assessment of the impact of the urban heat island intensity, Atmos. Environ., 63, 261-275, 2012.

Pal, S., Haeffelin, M., and Batchvarova, E.: Exploring a geophysical process-based attribution technique for the determination of the atmospheric boundary layer depth using aerosol lidar and near- surface meteorological measurements, J. Geophys. Res.-Atmos., 118, 1-19, doi:10.1002/jgrd.50710, 2013.

Radlach, M., Behrendt, A., and Wulfmeyer, V.: Scanning rotational Raman lidar at $355 \mathrm{~nm}$ for the measurement of tropospheric temperature fields, Atmos. Chem. Phys., 8, 159-169, doi:10.5194/acp-8-159-2008, 2008

Senff, C. J., Bösenberg, J., and Peters, G.: Measurement of water vapor flux profiles in the convective boundary layer with lidar and Radar-RASS, J. Atmos. Ocean. Tech., 11, 85-93, 1994.

Senff, C. J., Bösenberg, J., Peters, G., and Schaberl, T.: Remote sensing of turbulent ozone fluxes and the ozone budget in the convective boundary layer with DIAL and radar-RASS: a case study, Contrib. Atmos. Phys., 69, 161-176, 1996.

Sorbjan, Z.: Effects caused by varying the strength of the capping inversion based on a large eddy simulation model of the shearfree convective boundary layer, J. Atmos. Sci., 53, 2015-2024, 1996.

Sorbjan, Z: An evaluation of local similarity on the top of the mixed layer based on large-eddy simulations, Bound.-Lay. Meteorol., 101, 183-207, 2001.

Sorbjan, Z.: Statistics of scalar fields in the atmospheric boundary layer based on large-eddy simulations, Part I: free convection, Bound.-Lay. Meteorol., 116, 467-486, 2005.

Stull, R. B.: An Introduction to Boundary Layer Meteorology, Springer, Heidelberg, New York, 688 pp., 1988.

Träumner, K., Damian, Th., Stawiarski, Ch., and Wieser, A.: Turbulent Structures and Coherence in the Atmospheric Surface Layer, Bound.-Lay. Meteorol., 154, 1-25, doi:10.1007/s10546014-9967-6, 2015.

Turner, D. D., Ferrare, R. A., Wulfmeyer, V., and Scarino, A. J.: Aircraft evaluation of ground-Based Raman lidar water vapor turbulence profiles in convective mixed layers, J. Atmos. Ocean. Tech., 31, 1078-1088, doi:10.1175/JTECH-D-13-00075.1, 2014a.

Turner, D. D., Wulfmeyer, V., Berg, L. K., and Schween, J. H.: Water vapor turbulence profiles in stationary continental convective mixed layers, J. Geophys. Res., 119, 1-15, doi:10.1002/2014JD022202, 2014b.

Valdebenito, A. M., Pal, S., Lammel, G., Behrendt, A., and Wulfmeyer, V.: A novel approach for the characterisation of transport and optical properties of aerosol particles near sources: microphysics-chemistry-transport model development and application, Atmos. Environ., 45, 2981-2990, doi:10.1016/j.atmosenv.2010.09.004, 2011.

Wagner, G., Wulfmeyer, V., Späth, F., Behrendt, A., and Schiller, M.: Performance and specifications of a pulsed high-power single-frequency Ti:Sapphire laser for water-vapor differential absorption lidar, Appl. Optics, 52, 2454-2469, doi:10.1364/AO.52.002454, 2013.

Weckwerth, T. M., Wilson, J. W., and Wakimoto, R. M.: Thermodynamic variability within the convective boundary layer due to horizontal convective rolls, Mon. Weather Rev., 124, 769-784, 1996.

Whiteman, D. N., Demoz, B., Di Girolamo, P., Comer, J., Veselovskii, I., Evans, K., Wang, Z., Sabatino, D., Schwemmer, G., Gentry, B., Lin, R.-F., Behrendt, A., Wulfmeyer, V., Browell, E., Ferrare, R., Ismail, S., and Wang, J.: Raman Lidar Measurements during the International $\mathrm{H}_{2} \mathrm{O}$ Project. Part II: Case Studies, J. Atmos. Ocean. Tech., 23, 170-183, 2006. 
Wulfmeyer, V.: Investigations of humidity skewness and variance profiles in the convective boundary layer and comparison of the latter with large eddy simulation results, J. Atmos. Sci., 56, 1077-1087, 1999a.

Wulfmeyer, V.: Investigation of turbulent processes in the lower troposphere with water-vapor DIAL and radar-RASS, J. Atmos. Sci., 56, 1055-1076, 1999b.

Wulfmeyer, V. and Janjic, T.: 24-h observations of the marine boundary layer using ship-borne NOAA high-resolution Doppler lidar, J. Appl. Meteorol., 44, 1723-1744, 2005.

Wulfmeyer, V., Pal, S., Turner, D. D., and Wagner, E.: Can water vapour Raman lidar resolve profiles of turbulent variables in the convective boundary layer?, Bound.-Lay. Meteorol., 136, 253284, doi:10.1007/s10546-010-9494-z, 2010.
Wulfmeyer, V., Behrendt, A., Sorbian, Z., Turner, D. D., and Hardesty, R. M.: Determination of Convective Boundary Layer Entrainment Fluxes, Dissipation Rates, and the Molecular Destruction of Variances: Theoretical Description and a Strategy for its Confirmation with a Novel Lidar System Synergy, J. Atmos. Sci., under review, 2015.

Wyngaard, J. C.: Turbulence in the Atmosphere, Cambridge University Press, 2010.

Wyngaard, J. C. and Cote, O. R.: The budgets of turbulent kinetic energy and temperature variance in the atmospheric surface layer, J. Atmos. Sci., 28, 190-201, 1971. 